\title{
Prevalence and Force of Plasmodium Vivax and Plasmodium Falciparum Blood Stage Infection and Associated Clinical Malaria Burden in the Brazilian Amazon
}

Wuelton Monteiro ( $\nabla$ wueltonmm@gmail.com )

Fundacao de Medicina Tropical Doutor Heitor Vieira Dourado

Stephan Karl

Walter and Eliza Hall Institute of Medical Research

Andrea Kuehn Kuehn

Instituto de Salud Global de Barcelona

Anne Almeida

FMT

Michael White

Institut Pasteur

Sheila Vitor-Silva Vitor-Silva

Universidade do Estado do Amazonas Escola Superior de Artes e Turismo

Gisely Melo

FMTHVD

Djane Baia

FMT

Jose Diego Brito-Sousa

Fundacao de Medicina Tropical Doutor Heitor Vieira Dourado

Quique Bassat

Instituto de Salud Global de Barcelona

Ingrid Felger

university of basel

Ivo Mueller

University of Melbourne

Marcus Lacerda

FMT

Research 
Keywords: malaria, Brazilian Amazon, Plasmodium vivax, Plasmodium falciparum

Posted Date: August 3rd, 2020

DOI: https://doi.org/10.21203/rs.3.rs-51282/v1

License: (c) (1) This work is licensed under a Creative Commons Attribution 4.0 International License. Read Full License 


\section{Abstract}

Background: Plasmodium vivax and Plamodium falciparum are co-endemic in much of the Brazilian Amazon, with $P$. vivax comprising greater than $80 \%$ of clinical cases, especially in low transmission settings. The molecular force of blood-stage infection of $P$. vivax (molFOB) can provide a detailed picture of $P$. vivax transmission in low transmission settings and help improve malaria measures control and elimination efforts.

Methodology: Monthly samples were collected in a cohort of 1,274 individuals of all ages between April 2013 and March 2014 in three peri-urban communities in the Brazilian Amazon. Regression analyses were used to test how factors including age and community were associated with $P$. vivax molFOB, parasite positivity and clinical episodes.

Principal Findings: Respectively, $77.8 \%$ and $97.2 \%$ of the population remained free of $P$. vivax and $P$. falciparum infection. Expected heterozygosity for $P$. vivax was 0.69 for MSP1_F3 and 0.86 for MS2. Multiplicity of infection in $P$. vivax was close to the value of 1 as determined with both markers ( 1.06 for MSP1_F3 and 1.04 for MS2). Season was associated with $P$. vivax positivity [adjusted hazard ration (aHR) 2.6 (1.9-5.7)] and clinical disease [aHR 10.6 (2.4-47.2)]. P. falciparum infection was associated with previous malarial episodes [HR 9.7 (4.5-20.9)]. Subjects who reported bednet possession [incidence rate ratio (IRR) 1.6 (1.2-2.2)] or previous malaria episodes [IRR 3.0 (2.0-4.5)] were found to have significantly higher $P$. vivax molFOB.

Conclusions: Overall, $P$. vivax infection prevailed in the area and infections were mostly observed as monoclonal. High proportions of symptomatic and submicroscopic infections were found. Previous malaria episodes were associated with significantly higher $P$. vivax molFOB, likely indicating that effective radical cure is an important strategy to be addressed in these endemic communities.

\section{Introduction}

The global burden imposed by malaria remains high, with an estimated 219 million cases and 435,000 related deaths in 2017 [1]. Although malaria remains endemic in 91 countries, the majority of the burden (90\%) is confined to the African Region where Plasmodium falciparum predominates [1]. In the Americas, Plasmodium vivax is the predominant species causing over two thirds (69\%) of all cases in 2017. Despite most endemic countries in Latin America having achieved a reduction of incidence since 2010, there were still more than half a million $(562,300)$ cases in 2017, with Venezuela and Brazil accounting for more than half of these cases (65\%) [1]. Between 2005 and 2017 Brazil has achieved a $70 \%$ reduction of malaria cases, with $99 \%$ of all cases occurring in the Amazon region in 2017 [1,3]. Of special vulnerability are malaria-naïve individuals recently arrived from malaria-free areas and engaged in agricultural and forest-related activities such as logging, fishing and mining [4-7]. In the 1970s, increased industrial development demanded a large labor force, which evoked a large migratory influx to the peripheries of 
bigger cities such as Manaus. Such largely uncontrolled settlements have led to a gradual increase of malaria transmission in peri-urban areas [3].

Anopheles darlingi is the major malaria vector in the Amazon region, and has highly anthropophilic and endophagic behavior [8-11]. Current vector control measures primarily include the use of long-lasting insecticide-treated nets (LLINs) and indoor residual spraying (IRS), but there are little data from Latin America on the impact of vector control. One study showed that the use of LLINs was associated with malaria protection in the Amazon, however, it seemed to have a more protective effect against $P$. falciparum malaria in comparison with $P$. vivax malaria [7]. As in other regions, recent progress in malaria control in Brazil has been accompanied by an increasing proportion of cases caused by $P$. vivax, underscoring the challenges, namely relapses, yet to be addressed in control and management this species [12]. Understanding the epidemiology of relapses after primary infection is challenging, with an estimated $14-40 \%$ of individuals having detectable recurrences, even after treatment with primaquine $[7,13-16]$. A second challenge is the early production of $P$. vivax gametocytes, along with asymptomatic cases, which enables the transmission of parasites even before the infected individual develops clinical symptoms. Thirdly, $P$. vivax parasite densities are generally lower than those seen in $P$. falciparum infections, especially in hypoendemic areas such as in Brazil, therefore requiring more sensitive diagnostic tools [17]. Research has shown that a high proportion of submicroscopic and asymptomatic $P$. vivax infections usually exist in such settings, and that these infections can easily be missed by routine active and passive case detection [17]. It has been shown that asymptomatically infected individuals are able to infect mosquitoes of the Amazon region, therefore these infections might fuel residual malaria transmission, thereby complicating malaria elimination [18-21].

In view of these challenges to malaria elimination, it is important to gather data of spatial and temporal patterns of asymptomatic Plasmodium infections as well on gametocyte carriage from low-transmission settings. Therefore, in this study, we investigated risk factors and spatial-temporal patterns of incidence of Plasmodium infection and clinical malaria episodes in a peri-urban area of Manaus, Western Brazilian Amazon. We paid special attention to submicroscopic and asymptomatic infections by measuring the prevalence of $P$. falciparum and $P$. vivax blood-stage infections by PCR, the incidence of clinical cases, and estimating the molecular force of $P$. vivax blood-stage infection (molFOB) derived from molecular detection and genotyping of infections. Understanding the malaria epidemiology through $P$. vivax molFOB may provide a detailed assessment of malaria transmission by measuring individual exposure and its burden. Such information is of paramount importance when measuring intervention efficacy, host susceptibility and transmission patterns in low transmission and pre-elimination settings such as Brazil.

\section{Methods}

\section{Ethics statement}

This study was approved by the Brazilian National Committee of Ethics (CONEP) (349.211/2013) and the Committon of Ethine far rlininal Invoctination of tho Rarnolona Hospital Clinic (7306/2012). All Loading [MathJax]/jax/output/CommonHTML/fonts/TeX/fontdata.js 
participants were informed about the objectives of the study as well as the potential risks and benefits of their participation in the study. An informed consent form was signed by all study participants or by a parent or legal guardian in case of participants that were under 18 years of age. Children between 12 and 17 years of age signed an additional assent form. As routinely done, malaria patients received treatment with $25 \mathrm{mg} / \mathrm{kg}$ of chloroquine over a 3-day period $(10 \mathrm{mg} / \mathrm{kg}$ on day 0 and $7.5 \mathrm{mg} / \mathrm{kg}$ on days 1 and 2 . Primaquine was prescribed at the dosage of $0.5 \mathrm{mg} / \mathrm{kg}$ per day, during 7 days.

\section{Study design and subjects}

This cohort study was conducted in the Brasileirinho, Ipiranga and Puraquequara communities, located in Manaus peri-urban area, between April 2013 and March 2014 (Figure 1A). A detailed description of the study area has been presented elsewhere [17]. According to a census performed by a Fundação de Medicina Tropical Doutor Heitor Vieira Dourado (FMT-HVD) field team, the population of the study area was estimated to be approximately 2,400 inhabitants before the start of the study, in 2012. Each community has access to a malaria clinic for microscopy-based malaria diagnosis and treatment. A total of 1,200 participants of any age were enrolled into the study in April 2013.

\section{Data and sample collection}

For each study participant, a questionnaire was completed containing personal information such as age, gender, occupation, pregnancy, history of travel, as well as information on malaria preventive measures, previous malaria episodes and current health status. Upon enrolment and monthly during follow-up, finger-prick blood 151 samples $(\sim 300 \mu \mathrm{L})$ were collected using Microtainer ${ }^{\circledR}$ tubes containing EDTA and sodium fluoride (Becton Dickinson, USA). In infants, blood was obtained by either heel or toe puncture. Within one hour of collection, $50 \mu \mathrm{L}$ of blood were transferred into a reaction tube containing $250 \mu \mathrm{L}$ of RNAprotect (QIAGEN, Germany) in order to preserve RNA for downstream analyses [22] and $200 \mu \mathrm{L}$ of whole blood was transferred to another reaction tube. Samples were stored in cooling boxes until arrival in the laboratory, where the $200 \mu \mathrm{L}$ sample was separated into a red blood cell (RBC) pellet and plasma. All samples were frozen at $-80^{\circ} \mathrm{C}$ until further processing. If the collected blood volume was $<250 \mu \mathrm{L}$, the actual volume was recorded.

\section{Clinical symptoms}

In the case of symptoms related to malaria or in 161 the case of increased body temperature $\left(>37.5^{\circ} \mathrm{C}\right)$, a thick blood smear (TBS) was prepared according to World Health Organization guidelines [23]. When positive for malaria, appropriate treatment was provided in accordance with the national guidelines of the Brazilian Ministry of Health [24]. An asymptomatic infection was defined as presence of a malarial infection by TBS, but absence of fever and any other malaria related symptoms (chills, sweating, headache, vomit, abdominal pain) at the moment of sample collection, or anytime in the preceding 48 hours. 
Pelleted RBCs, obtained from $200 \mu \mathrm{L}$ of whole blood, were re-suspended in PBS and genomic DNA was extracted using FavorPrep 96-well Genomic DNA Kit (Favorgen, Taiwan) according to the manufacturer's instructions. DNA was eluted with $2 \times 100 \mu \mathrm{L}$ of elution buffer and stored at $-20^{\circ} \mathrm{C}$ until assayed by PCR. If the amount of whole blood available for DNA extraction was $\leq 100 \mu \mathrm{L}$, the DNA volume was vacuum concentrated until reaching the original blood volume recorded. RNA from $50 \mu \mathrm{L}$ whole blood, stored in RNAprotect, was extracted using RNeasy Plus 96-well kit (QIAGEN, Germany) and eluted in $50 \mu \mathrm{L}$ RNasefree $\mathrm{dH} 2 \mathrm{O}$ as described previously [22]. All DNA samples were subject to a generic Plasmodium species (QMAL) qPCR targeting a conserved region of the 18S rRNA gene [22]. QMAL-positive samples were further analysed by species-specific qPCR assays targeting the18S rRNA genes of $P$. falciparum and $P$. vivax, as previously described [22,25]. For detection of $P$. falciparum, a modified reverse primer was used [26]. For quantification of $18 \mathrm{~S}$ rRNA gene copy numbers, in each experiment three dilutions of control plasmids containing the respective amplicons were included in triplicates $(102,104$ and 106 copies/ $\mu \mathrm{L})$. For genotyping individual $P$. vivax clones, the molecular markers msp1F3 and MS16 were typed using capillary electrophoresis for highly precise fragment sizing allowing for longitudinal follow up of individual parasite clones. Details of the genotyping methods have been described previously [27]. RTqPCR assays were performed on RNAs from all $P$. vivax and/or $P$. falciparum positive samples to detect gametocyte-specific transcripts of the pvs25 ( $P$. vivax) and pfs25 ( $P$. falciparum) genes. For quantification of pvs 25 and pfs 25 transcript numbers, control plasmids containing the amplified region were included as standards in each run. All qPCR and RT-qPCR assays were performed on a 7500 Fast Real-Time PCR System (Applied Biosystems).

\section{Statistical analysis}

Data from questionnaires were imported into databases using Cardiff TeleForm version 10.4.1 (Cardiff Software). Individual databases were combined in Microsoft Access 2010. For incidence calculations (molFOB and clinical malaria incidence), subject data were censored on the last visit before two consecutively missed scheduled follow-up visits in order to reduce bias [28]. Differences in proportions were tested for statistical significance using the McNemar X2 test with continuity correction. To achieve normal distribution, qPCR densities were expressed as log10-transformed 18S rRNA genomic copies/ $\mu \mathrm{L}$ blood for asexual parasites, and log10-transformed pfs 25 or pvs 25 transcripts/ $\mu \mathrm{L}$ blood for gametocytes. Geometric means of densities were calculated. Differences in densities of asexual or sexual-stage parasites were tested for statistical significance using Welch's two-sample t-test.

The molecular force of new $P$. vivax blood-stage infections (molFOB) was calculated by counting the number of genotypes observed at each visit, that had not been present in the preceding two visits (0-0-1 patterns) and adjusting these counts by the respective times-at-risk. molFOB for $P$. vivax was determined for both genetic markers combined. Negative binomial regression models were used to assess the influence of different risk-factors on the incidence of $P$. vivax and $P$. falciparum gametocyte positivity as previously described, using positivity counts and times-at-risk over the entire period of observation [28]. Since moIFOB is a count variable measured per individual over a specific exposure time (time at risk), and 
used as offset. If we define $\mu \mathrm{j}$ as the log of the number of genotypes at visit $j$, then for each infection pattern $\mathrm{j}(0-0-0$ or $0-0-1)$ we have $\mu \mathrm{j}=\exp (\beta x j+$ offsetj $+v j)$, where $\beta$ is a vector of regression coefficients, offsetj=log(exposure time) and vj follows a gamma distribution (to give a negative binomial distribution). Incidence rate ratios (IRR) and adjusted IRR (aIRR) were calculated with their respective $95 \%$ confidence intervals. Because using the collapsed data to model molFOB for each individual does not allow for the analysis of time-changing covariates, factors influencing frequency of parasite positivity and frequency of clinical episodes within the study period were explored using multiple failure time models allowing for time-changing covariates [29]. For multiple failure time models, hazard rate ratios (HRR) are calculated with $95 \%$ confidence intervals. In these models, parasite positivity and clinical episodes were equivalent to a 'failed' outcome, respectively. In addition to the adjusted statistical models presented in the main manuscript, univariate analyses and multivariate analyses with backward selection are provided as Supplemental Materials. Versions of each model analysis were implemented with backwards selection to eliminate non-significant covariates resulting in the most parsimonious models. Statistical analyses were conducted using R v3.1.1 or STATA v14.

\section{Results}

\section{Study population}

A total of 1,274 individuals were enrolled at the beginning of the study. A total of $51.1 \%$ (651) were males and approximately half were aged between 18 and 59 years old $(634 ; 49.7 \%)$. Nearly $40 \%(504)$ of the subjects claimed to have had at least 3 malaria episodes during their lifetime. A total of 17 individuals $(1.3 \%)$ had experienced a malaria infection in the preceding two weeks and $40(3.2 \%)$ had taken antimalarial drugs in the past two months. A total of 1,201 subjects $(94.9 \%)$ had resided for more than 2 months in the study area. The number of individuals enrolled was similar in the three communities, Brasileirinho $(n=430)$, Ipiranga $(n=416)$ and Puraquequara $(n=428)$. Characteristics of the study population are summarized in Table 1.

\section{Prevalence by active case detection}

Monthly P. vivax prevalence by qPCR ranged from 2.5\% in June 2013 to $6.5 \%$ in November 2013 (Figure 2A). P. falciparum was not detected in August and September 2013, with the highest prevalence ( 1.0\%) occurring in March 2014 (Figure 2B). Both species presented a similar seasonality profile, with a higher prevalence of $P$. vivax from October to February, and of $P$. falciparum from November to March, coinciding with the rainy season (Figure 2D). P. vivax asymptomatic infections predominated in Puraquequara community, although clinical cases were mostly seen in Ipiranga. For $P$. falciparum, asymptomatic infections and clinical cases were both predominant in the Ipiranga community.

\section{Risk factors associated with $P$. vivax positivity}

In the multivariate analysis shown in Table 2, P. vivax infection was associated with the rainy season 
living in Puraquequara having aHR $=2.4(1.1-2.3)$ compared to Ipiranga. Age was associated with $P$. vivax infection $(P=0.001)$, with individuals aged $20-60$ years having aHR $=2.2(1.1,2.5)$ compared to children under 10 years. Bed net usage was significantly associated with higher $P$. vivax positivity [aHR $=$ 1.06 (1.01-1.08), $\mathrm{P}=0.005]$. Indoor residual spraying (IRS) in the house was associated with lower risk of $P$. vivax infection.

\section{Risk factors associated with $P$. vivax clinical disease}

P. vivax clinical disease was associated with the rainy season [(aHR: 10.6 (2.4-47.2), $\mathrm{P}=0.002)]$ (Table 2). Living in the Brasileirinho [(aHR: $0.11(0.05-0.23), P<0.001)$ ] and Puraquequara [(aHR: 0.26 (0.14-0.50), $P<0.001)]$ communities, working in agriculture [(aHR: $0.43(0.25-0.74), P=0.002)]$, and living in a house treated with IRS [(aHR: $0.92(0.86-0.98), P=0.008)]$ were all variables associated with a reduced risk of clinical malaria disease.

\section{Risk factors associated with $P$. falciparum positivity}

P. falciparum infection was associated with community $(P<0.001)$, with individuals living in Brasilerinho $[\mathrm{aHR}=0.04(0.01-0.26)]$ and Puraquequara $[\mathrm{aHR}=0.23(0.07-0.71)]$ having lower positivity than individuals in Ipiranga. Individuals with previous malarial episodes had significantly higher $P$. falciparum positivity [(aHR: $9.7(4.5-20.9), \mathrm{P}<0.001)]$.

\section{Genetic Diversity and Multiplicity of Infections}

The heterogeneity in the incidence of malaria infections is shown in Figure 3A. Both $P$. vivax and $P$. falciparum infections were restricted to a small proportion of the study population. Overall, $77.8 \%$ of the population remained free of $P$. vivax infection and $97.2 \%$ of the population remained free of $P$. falciparum infection over the course of the study period. Based on the two markers (MSP1 F3 and MS2), expected heterozygosity for P. vivax was 0.69 (MSP1_F3) and 0.86 (MS2), respectively. Overall, the multiplicity of infection was close to the value of 1 as determined with both markers (1.06 for MSP1_F3 and 1.04 for MS2, respectively), indicating that infections were mostly observed as monoclonal. Figure 3B shows the $P$. vivax molFOB over the entire year of follow-up. Similarly, new $P$. vivax infections were restricted to approximately $20 \%$ of the study population, whereas $80 \%$ did not receive new infections. Of individuals who had any $P$. vivax infection, the majority had molFOB $=1$ to 2 . The maximum number of genetically distinct infections/individual/year was molFOB $=5$.

\section{Factors associated with $P$. vivax molFOB}

Table 3 shows the results of the multivariate negative binomial model applied to the molecular force of blood-stage infection of $P$. vivax. molFOB was significantly associated with community $(\mathrm{P}<0.001)$. $P$. vivax molFOB was lowest in the Brasileirinho community with aIRR $=0.47(0.31-0.71)$ compared to Ipiranga. No significant difference in $P$. vivax molFOB was observed between Ipiranga and Puraquequara communities. Increased $P$. vivax molFOB was significantly associated with reported bed net possession

Loading [MathJax]/jax/output/CommonHTML/fonts/TeX/fontdata.js jisodes [(aIRR:3.02 (2.02-4.53), P<0.001)]. 


\section{Discussion}

The present study highlights well-known differences in the epidemiology of $P$. vivax and $P$. falciparum, evaluating the incidence of Plasmodium spp. and clinical cases of malaria in peri-urban communities in the Brazilian Amazon and estimate the P. vivax molFOB in low transmission settings in the Americas. Previous studies have measured molFOB in Papua New Guinean children in observational and randomized clinical trial cohorts, and have related incidence of clinical infection and other factors to this measure $[30,31]$. The main factors related to $P$. falciparum molFOB in these earlier studies were seasonality, village of residence and age [30-33]. As for $P$. vivax, molFOB was strongly associated with incidence of clinical episodes and a high molFOB likely resulted in rapid acquisition of immunity against P. vivax in children [31].

Recent studies in the Amazon region and other malaria endemic areas in the world have shown a high proportion of submicroscopic $P$. vivax infections $[7,17,34]$. In the present study, factors associated with $P$. vivax positivity were age (20-60 years), seasonality, use of mosquito nets and IRS. In the Brasileirinho, Ipiranga and Puraquequara communities, the distribution of mosquito nets and IRS is mainly focused on areas where there are many cases of malaria (ascertained by active and passive case detection, registered by the SIVEP-Malaria platform). However, this measure may not have been effective in preventing infection in these areas, or it may not be sufficient to decrease $P$. vivax positivity, since many infections may derive from hypnozoites rather than new infections, as suggested by a study in Papua New Guinea [32].

A higher prevalence of malaria infection in the rainy season was also shown in previous studies, corroborating what has already been described for other regions of the Amazon [34,35]. The predictors of $P$. vivax clinical disease found in our study were seasonality, and marginally, frequency of travel and use of mosquito nets. Koepfli [31] also found the seasonality to be a predisposing factor in clinical disease by P. vivax. Protective factors of clinical disease such as being over 60 years old and working in agriculture may be associated to prolonged exposure to $P$. vivax infection during lifetime. Due to age- and exposuredependent acquired immunity, clinical presentation of malaria becomes rarer in relation to age, thus increasing the number of asymptomatic carriers [31,36].

We also observed that $P$. vivax prevalence and molFOB in the study area were higher and less affected by seasonality as compared to $P$. falciparum. Whereas $P$. vivax prevalence and molFOB peaked in November in Ipiranga community, transmission indicators remained more stable throughout the entire observational period in the other two communities, with almost no seasonality observed in Brasileirinho. In contrast, the annual $P$. falciparum prevalence profile was characterized by a very sharp peak in January in Ipiranga community during which the observed prevalence increased by almost 10-fold alongside a sharp rise of clinical malaria cases. In fact, nearly all clinical cases observed in the present study occurred during this period and in Ipiranga community. The outbreak caused by $P$. falciparum subsided by April and the remainder of the observational period was characterized by very low $P$. falciparum prevalence in all three 
communities. These observed differences in the seasonality profiles of the two species indicate a more stable transmission of $P$. vivax in contrast to in contrast to a more unstable transmission of $P$. falciparum.

The overall lower $P$. vivax parasite densities are close to the threshold of detection of even molecular diagnostic tests, thus hampering the characterization of the true incidence of new infections detected by genotyping, as reported elsewhere [37,38]. Therefore, estimation of molFOB can be dominated by clones with higher parasite densities, while low density, sub-dominant clones may not be detected, especially if they have arisen from relapses. As such, the molFOB reported in this study is likely an underestimation of the true force of blood-stage infection.

In conclusion, $P$. vivax infection prevailed in the area and infections were mostly observed as monoclonal. High proportions of symptomatic and submicroscopic infections were also found. Previous malaria episodes were associated with significantly higher $P$. vivax molFOB, likely indicating that effective radical cure is an important strategy to be addressed in these endemic communities. Asymptomatic and submicroscopic infections pose substantial challenges for $P$. vivax malaria control, hampering accurate surveillance efforts needed to pursue elimination, especially in low transmission settings.

\section{Declarations}

\section{Acknowledgements}

We would like to thank the all participants from the communities of Brasileirinho, Ipiranga and Praquequara, for their willingness to participate in the study. We also thank all healthcare workers from the Malaria Department at the Fundação de Medicina Tropical Heitor Vieira Dourado as well as the Fundação de Vigilância em Saúde (FVS) for their assistance with field work.

\section{Funding}

This work was supported by a grant from Bill \& Melinda Gates Foundation to the TransEPI consortium. Additional support was provided by Fundação de Amparo à Pesquisa do Estado do Amazonas (FAPEAM; PAPAC - EDITAL No 005/2019, Pró-Estado, Posgrad and PAPAC ), Brazil and NHMRC (\#1043345). JDBS is supported by the Coordenação de Aperfeicoamento de Pessoal de Nível superior - Brasil (CAPES) Finance Code 001. ISGlobal is a member of the CERCA Programme, Generalitat de Catalunya (http://cerca.cat/en/suma/). CISM is supported by the Government of Mozambique and the Spanish Agency for International Development (AECID). The funders had no role in the study design, data collection and analysis, decision to publish, or preparation of the manuscript. WMM and MVGL are CNPq fellows.

\section{Author contributions}

Conceptualization: WMM IM MVGL 
Writing - Original Draft Preparation: DCBS WMM SK ACGA JDBS

Writing - Review \& Editing: WMM SK DCBS AK ACGA MW SVS GCM JDBS QB IF IM MVGL

\section{References}

1. World Health Organization. World Malaria Report 2018. Geneva: World Health Organization. 2018.

2. Alonso P, Noor AM. The global fight against malaria is at crossroads. The Lancet. 2017; 390:2532-4.

3. Sampaio VS, Siqueira AM, Alecrim M das GC, Mourão MPG, Marchesini PB, Albuquerque BC, et al. Malaria in the state of amazonas: A typical brazilian tropical disease influenced by waves of economic development. Rev Soc Bras Med Trop. 2015; 48:4-11.

4. Camargo LMA, Ferreira MU, Krieger H, De Camargo EP, Da Silva LP. Unstable hypoendemic malaria in Rondônia (Western Amazon Region, Brazil): Epidemic outbreaks and work-associated incidence in an agro-industrial rural settlement. Am J Trop Med Hyg. 1994; 51:16-25.

5. Silva-Nunes M, Codeço CT, Malafronte RS, Da Silva NS, Juncansen C, Muniz PT, et al. Malaria on the amazonian frontier: Transmission dynamics, risk factors, spatial distribution, and prospects for control. Am J Trop Med Hyg. 2008; 79:624- 35.

6. Parker BS, Paredes Olortegui M, Peñataro Yori P, Escobedo K, Florin D, Rengifo Pinedo S, et al. Hyperendemic malaria transmission in areas of occupation-related travel in the Peruvian Amazon. Malar J. 2013; 12:178.

7. Vitor-Silva S, Siqueira AM, de Souza Sampaio V, Guinovart C, Reyes-Lecca RC, de Melo GC, et al. Declining malaria transmission in rural Amazon: changing epidemiology and challenges to achieve elimination. Malar J. 2016; 15:266.

8. Klein TA, Lima JBP. Seasonal distribution and biting patterns of Anopheles mosquitoes in Costa Marques, Rondônia, Brazil. J Am Mosq Control Assoc. 1990; 6:700-7.

9. Lourenço-de-Oliveira R, Guimarães E, Arle M, Silva TF, Castro MG, Motta MA, et al. Anopheline species, some of their habits and relation to malaria in endemic areas of Rondônia State, Amazon region of Brazil. Mem Inst Oswaldo Cruz. 1989; 84:501-14.

10. Martins-Campos KM, Pinheiro WD, Vítor-Silva S, Siqueira AM, Melo GC, Rodrigues ÍC, et al. Integrated vector management targeting Anopheles darlingi populations decreases malaria incidence in an unstable transmission area, in the rural Brazilian Amazon. Malar J. 2012; 11:351.

11. Tadei W, Santos J, Costa W, Scarpassa V. Biology of Amazonian Anopheles. XII. Occurrence of Anopheles species, transmission dynamics and malaria control in the urban area of Ariquemes (Rondônia). Rev Inst Med Trop Sao Paulo. 1988; 30:221-51.

12. Siqueira AM, Mesones-Lapouble O, Marchesini P, Sampaio VDS, Brasil P, Tauil PL, et al. Plasmodium vivax landscape in Brazil: Scenario and challenges. Am J Trop Med Hyg. 2016; 95:87-96. 
13. Boulos M, Amato-Neto V, Dutra A, Di Santi S, Shiroma M. Frequency of malaria relapse due to Plasmodium vivax in a non-endemic region (São Paulo, Brazil). Rev Inst Med Trop Sao Paulo. 1991; 33:143-6.

14. Duarte EC, Pang LW, Ribeiro LC, Fernandes Fontes CJ. Association of subtherapeutic dosages of a standard drug regimen with failures in preventing relapses of vivax malaria. Am J Trop Med Hyg. 2001; 65:471-6.

15. Pedro RS, Guaraldo L, Campos DP, Costa AP, Daniel-Ribeiro CT, Brasil P. Plasmodium vivax malaria relapses at a travel medicine centre in Rio de Janeiro, a non-endemic area in Brazil. Malar J. 2012; 11:245.

16. Simões LR, Alves Jr ER, Ribatski-Silva D, Gomes LT, Nery AF, Fontes CJF. Factors associated with recurrent Plasmodium vivax malaria in Porto Velho, Rondônia State, Brazil, 2009. Cad Saude Publica. 2014; 30:1403-17.

17. Almeida ACG, Kuehn A, Castro AJM, Vitor-Silva S, Figueiredo EFG, Brasil LW, et al. High proportions of asymptomatic and submicroscopic Plasmodium vivax infections in a peri-urban area of low transmission in the Brazilian Amazon. Parasites and Vectors. 2018; 11:194.

18. Alves FP, Gil LHS, Marrelli MT, Ribolla PEM, Camargo EP, Silva LHP. Asymptomatic Carriers of Plasmodium spp. as Infection Source for Malaria Vector Mosquitoes in the Brazilian Amazon. J Med Entomol. 2005; 42:777-9.

19. Barbosa S, Gozze AB, Lima NF, Batista CL, Bastos MS, Nicolete VC, et al. Epidemiology of Disappearing Plasmodium vivax Malaria: A Case Study in Rural Amazonia. PLoS Negl Trop Dis. 2014; 8:e3109.

20. Lima NF, Bastos MS, Ferreira MU. Plasmodium vivax: Reverse transcriptase realtime PCR for gametocyte detection and quantitation in clinical samples. Exp Parasitol. 2012; 132:348-54.

21. Martins-Campos KM, Kuehn A, Almeida A, Duarte APM, Sampaio VS, Rodriguez ÍC, et al. Infection of Anopheles aquasalis from symptomatic and asymptomatic Plasmodium vivax infections in Manaus, western Brazilian Amazon. Parasites Vect. 2018; 11:288.

22. Wampfler R, Mwingira F, Javati S, Robinson L, Betuela I, Siba P, et al. Strategies for Detection of Plasmodium species Gametocytes. PLoS One. 2013; 8:e76316.

23. World Health Organization. Basic malaria microscopy: part I. learner's guide. Basic Malaria Microscopy: Part I. Geneva: World Health Organization. 2010.

24. Brazilian Ministry of Health. Guia prático de tratamento da malária no Brasil. Brasília: Ministério da Saúde. 2010; 36.

25. Rosanas-Urgell A, Mueller D, Betuela I, Barnadas C, Iga J, Zimmerman PA, et al. Comparison of diagnostic methods for the detection and quantification of the four sympatric Plasmodium species in field samples from Papua New Guinea. Malar J. 2010; 9:361.

26. Perandin F, Manca N, Calderaro A, Piccolo G, Galati L, Ricci L, et al. Development of a Real-Time PCR Assay for Detection of Plasmodium falciparum, Plasmodium vivax, and Plasmodium ovale for 
27. Koepfli C, Timinao L, Antao T, Barry AE, Siba P, et al. A Large Plasmodium vivax Reservoir and Little Population Structure in the South Pacific. PLoS ONE. 2013; 8: e66041.

28. Wampfler R, Hofmann NE, Karl S, Betuela I, Kinboro B, Lorry L, et al. Effects of liver-stage clearance by Primaquine on gametocyte carriage of Plasmodium vivax and P. falciparum. PLoS Negl Trop Dis. 2017; $11: \mathrm{e} 0005753$.

29. Therneau T, Grambsch P. Modeling Survival Data: Extending the Cox Model. Technometrics. 2002.

30. Mueller I, Schoepflin S, Smith TA, Benton KL, Bretscher MT, Lin E, et al. Force of infection is key to understanding the epidemiology of Plasmodium falciparum malaria in Papua New Guinean children. Proc Natl Acad Sci. 2012; 109:10030-5.

31. Koepfli C, Colborn KL, Kiniboro B, Lin E, Speed TP, Siba PM, et al. A High Force of Plasmodium vivax Blood-Stage Infection Drives the Rapid Acquisition of Immunity in Papua New Guinean Children. PLoS Negl Trop Dis. 2013; 7:e2403.

32. Robinson LJ, Wampfler R, Betuela I, Karl S, White MT, Li Wai Suen CSN, et al. Strategies for Understanding and Reducing the Plasmodium vivax and Plasmodium ovale Hypnozoite Reservoir in Papua New Guinean Children: A Randomised Placebo-Controlled Trial and Mathematical Model. PLoS Med. 2015; 12:e1001891.

33. Hofmann NE, Karl S, Wampfler R, Kiniboro B, Teliki A, Iga J, et al. The complex relationship of exposure to new Plasmodium infections and incidence of clinical malaria in Papua New Guinea. Cooper B, editor. Elife. 2017; 6:e23708.

34. Rovira-Vallbona E, Contreras-Mancilla JJ, Ramirez R, Guzmán-Guzmán M, Carrasco-Escobar G, Llanos-Cuentas A, et al. Predominance of asymptomatic and sub-microscopic infections characterizes the Plasmodium gametocyte reservoir in the Peruvian Amazon. PLoS Negl Trop Dis. 2017; 11:e0005674.

35. Wolfarth BR, Filizola N, Tadei WP, Durieux L. Epidemiological analysis of malaria and its relationships with hydrological variables in four municipalities of the State of Amazonas, Brazil. Hydrol Sci J. 2013; 58:1495-1504.

36. Smith T, Felger I, Tanner M, Beck HP. Premunition in Plasmodium falciparum infection: insights from the epidemiology of multiple infections. Trans R Soc Trop Med Hyg. 1999; 93:59-64.

37. Koepfli C, Schoepflin S, Bretscher M, Lin E, Kiniboro B, Zimmerman PA, et al. How much remains undetected? probability of molecular detection of human Plasmodia in the field. PLoS One. 2011; 6:e19010.

38. Felger I, Maire M, Bretscher MT, Falk N, Tiaden A, Sama W, et al. The Dynamics of Natural Plasmodium falciparum Infections. PLoS One. 2012; 7:e45542.

\section{Tables}


Table 1.

Baseline characteristics of the population enrolled in the study.

\begin{tabular}{|c|c|c|}
\hline \multirow[t]{2}{*}{ Variable } & \multicolumn{2}{|c|}{ Participants } \\
\hline & Number & $\%$ \\
\hline Total & 1,274 & 100.0 \\
\hline \multicolumn{3}{|l|}{ Gender } \\
\hline Male & 651 & 51.1 \\
\hline Female & 623 & 48.9 \\
\hline \multicolumn{3}{|l|}{ Age group (years) } \\
\hline$<10$ & 368 & 28.9 \\
\hline $10-20$ & 634 & 49.6 \\
\hline $21-60$ & 128 & 10.0 \\
\hline$\geq 61$ & 160 & 12.5 \\
\hline \multicolumn{3}{|l|}{ Occupation } \\
\hline Agriculture & 179 & 14.1 \\
\hline Office worker & 170 & 13.3 \\
\hline House wife & 218 & 17.1 \\
\hline Pre-school children & 175 & 13.7 \\
\hline School children & 331 & 26.0 \\
\hline Retired & 63 & 5.0 \\
\hline Unemployed/Other & 138 & 10.8 \\
\hline \multicolumn{3}{|c|}{ Previous infection (number) in the last two months } \\
\hline 0 & 406 & 31.9 \\
\hline $1-3$ & 364 & 28.6 \\
\hline$>3$ & 504 & 39.6 \\
\hline \multicolumn{3}{|l|}{ Infection in past two weeks } \\
\hline Yes & 17 & 1.3 \\
\hline No & 1,251 & 98.7 \\
\hline \multicolumn{3}{|l|}{ Antimalarial in past two months } \\
\hline /jax/output/CommonHTML/fonts/TeX/fontdata.js & 40 & 3.2 \\
\hline
\end{tabular}




\begin{tabular}{|c|c|c|}
\hline No & 1,229 & 96.8 \\
\hline \multicolumn{3}{|c|}{ More than 2 months of residency } \\
\hline Yes & 1,201 & 94.9 \\
\hline No & 65 & 5.1 \\
\hline \multicolumn{3}{|l|}{ Community } \\
\hline Ipiranga & 430 & 33.8 \\
\hline Brasileirinho & 416 & 32.7 \\
\hline Puraquequara & 428 & 33.6 \\
\hline
\end{tabular}


Table 2.

Risk factors associated with $P$. vivax positivity, $P$. vivax clinical disease, and $P$. falciparum positivity. Adjusted hazards ratio (aHR) was calculated using a multiple failure time model.

\begin{tabular}{|c|c|c|c|c|c|c|}
\hline \multirow[t]{2}{*}{ Risk factor } & \multicolumn{2}{|c|}{ P. vivax positivity } & \multicolumn{2}{|c|}{ P. vivax clinical disease } & \multicolumn{2}{|l|}{$\begin{array}{l}\text { P. falciparum } \\
\text { positivity }\end{array}$} \\
\hline & aHR & p & aHR & $\mathrm{p}$ & aHR & $\mathbf{p}$ \\
\hline \multicolumn{7}{|l|}{$\begin{array}{l}\text { Community (ref. } \\
\text { Ipiranga) }\end{array}$} \\
\hline Season (Ref: Jun-Nov) & $\begin{array}{l}2.56(1.89- \\
5.74)\end{array}$ & $<0.001$ & $\begin{array}{l}10.56(2.36- \\
47.19)\end{array}$ & 0.002 & $\begin{array}{l}0.08(0.01- \\
0.51)\end{array}$ & 0.008 \\
\hline \multicolumn{7}{|l|}{$\begin{array}{l}\text { Community (ref. } \\
\text { Ipiranga) }\end{array}$} \\
\hline Brasileirinho & $\begin{array}{l}1.01(0.4- \\
1.08)\end{array}$ & 0.002 & $\begin{array}{l}0.11(0.05- \\
0.23)\end{array}$ & $<0.001$ & $\begin{array}{l}0.04(0.01- \\
0.26)\end{array}$ & $<0.001$ \\
\hline Puraquequara & $\begin{array}{l}2.39(1.11- \\
2.31)\end{array}$ & & $\begin{array}{l}0.26(0.14- \\
0.5)\end{array}$ & & $\begin{array}{l}0.23(0.07- \\
0.71)\end{array}$ & \\
\hline \multicolumn{7}{|l|}{ Age group (ref. 1-10) } \\
\hline $10-20$ & $\begin{array}{l}1.36(0.78- \\
1.95)\end{array}$ & & $\begin{array}{l}1.01(0.54- \\
1.88)\end{array}$ & 0.02 & $\begin{array}{l}0.78(0.19- \\
3.27)\end{array}$ & \\
\hline $21-60$ & $\begin{array}{l}2.22(1.1- \\
2.45)\end{array}$ & 0.001 & $\begin{array}{l}0.63(0.36- \\
1.13)\end{array}$ & & $\begin{array}{l}1.33(0.39- \\
4.5)\end{array}$ & 0.300 \\
\hline$\geq 61$ & $\begin{array}{l}1.9(0.71- \\
2.15)\end{array}$ & & $\begin{array}{l}0.15(0.04- \\
0.63)\end{array}$ & & $\begin{array}{l}2.15(0.47- \\
9.94)\end{array}$ & \\
\hline $\begin{array}{l}\text { Employed in } \\
\text { agriculture }^{1}\end{array}$ & $\begin{array}{l}0.82(0.52- \\
1.12)\end{array}$ & 0.162 & $\begin{array}{l}0.43(0.25- \\
0.74)\end{array}$ & 0.002 & $\begin{array}{l}1.48(0.41- \\
5.29)\end{array}$ & 0.546 \\
\hline Male & $\begin{array}{l}1.21(0.91- \\
1.62)\end{array}$ & 0.187 & $\begin{array}{l}1.16(0.77- \\
1.75)\end{array}$ & 0.482 & $1(0.4-2.47)$ & 0.996 \\
\hline Bednet usage $^{2,3}$ & $\begin{array}{l}1.06(1.01- \\
1.08)\end{array}$ & 0.005 & $\begin{array}{l}1.06(1.01- \\
1.11)\end{array}$ & 0.018 & $\begin{array}{l}0.95(0.85- \\
1.06)\end{array}$ & 0.322 \\
\hline Travel frequency ${ }^{2}$ & $\begin{array}{l}0.99(0.99- \\
1.01)\end{array}$ & 0.516 & $1.01(1-1.01)$ & 0.02 & $\begin{array}{l}1(0.95- \\
1.05)\end{array}$ & 0.934 \\
\hline $\begin{array}{l}\text { House treated with } \\
\text { IRS }^{2}\end{array}$ & $\begin{array}{l}0.96(0.92- \\
0.99)\end{array}$ & 0.022 & $\begin{array}{l}0.92(0.86- \\
0.98)\end{array}$ & 0.008 & $\begin{array}{l}1.08(0.94- \\
1.23)\end{array}$ & 0.278 \\
\hline $\begin{array}{l}\text { Windows protected by } \\
\text { screen }^{1}\end{array}$ & $\begin{array}{l}0.78(0.72- \\
1.37)\end{array}$ & 0.958 & $\begin{array}{l}1.56(0.87- \\
2.8)\end{array}$ & 0.135 & $\begin{array}{l}1.05(0.27- \\
4.08)\end{array}$ & 0.946 \\
\hline $\begin{array}{l}\text { Reported previous } \\
\text { malaria }\end{array}$ & $\begin{array}{l}1.11(0.56- \\
1.58)\end{array}$ & 0.814 & $\begin{array}{l}0.66(0.17- \\
2.64)\end{array}$ & 0.558 & $\begin{array}{l}9.65(4.45- \\
20.92)\end{array}$ & $<0.001$ \\
\hline
\end{tabular}


1: status at enrolment; 2: as time-changing covariate (average observed at time of outcome); 3: average bednet usage was defined as the proportion of times a person had answered 'yes' to the question: 'Did you sleep under a bednet last night' during ACD; IRS, indoor residual spraying.

Table 3.

Factors associated with P. vivax molecular force of infection (molFOB). Adjusted incidence rate ratio (alRR) was calculated using a Negative Binomial regression model.

\begin{tabular}{|c|c|c|}
\hline \multirow[t]{2}{*}{ Risk factor } & \multicolumn{2}{|l|}{ P. vivax mol $F O B$} \\
\hline & aHR & $\mathbf{P}$ \\
\hline \multicolumn{3}{|l|}{ Community (ref. Ipiranga) } \\
\hline Brasileirinho & $0.47(0.31-0.71)$ & \multirow[t]{2}{*}{$<0.001$} \\
\hline Puraquequara & $0.98(0.69-1.39)$ & \\
\hline \multicolumn{3}{|l|}{ Age group (ref. 1-10) } \\
\hline $10-20$ & $1.15(0.73-1.82)$ & \\
\hline $21-60$ & $1.06(0.71-1.60)$ & 0.420 \\
\hline$\geq 61$ & $0.75(0.43-1.29)$ & \\
\hline Employed in agriculture $^{1}$ & $1.22(0.81-1.83)$ & 0.350 \\
\hline Male & $1.20(0.91-1.58)$ & 0.200 \\
\hline Bednet usage $^{2,3}$ & $1.63(1.24-2.15)$ & $<0.001$ \\
\hline Travel frequency ${ }^{2}$ & $1.00(0.92-1.10)$ & 0.950 \\
\hline House treated with IRS ${ }^{2}$ & $0.88(0.66-1.16)$ & 0.360 \\
\hline Windows protected by screen ${ }^{1}$ & $1.04(0.74-1.45)$ & 0.840 \\
\hline Reported previous malaria & $3.02(2.02-4.53)$ & $<0.001$ \\
\hline
\end{tabular}

1: status at enrolment; 2: as time-changing covariate (average observed at time of outcome); 3 : average bednet usage was defined as the proportion of times a person had answered yes' $\rightarrow$ thequestion: Did you sleep under a bednet last night' during ACD; IRS, indoor residual spraying.

\section{Figures}



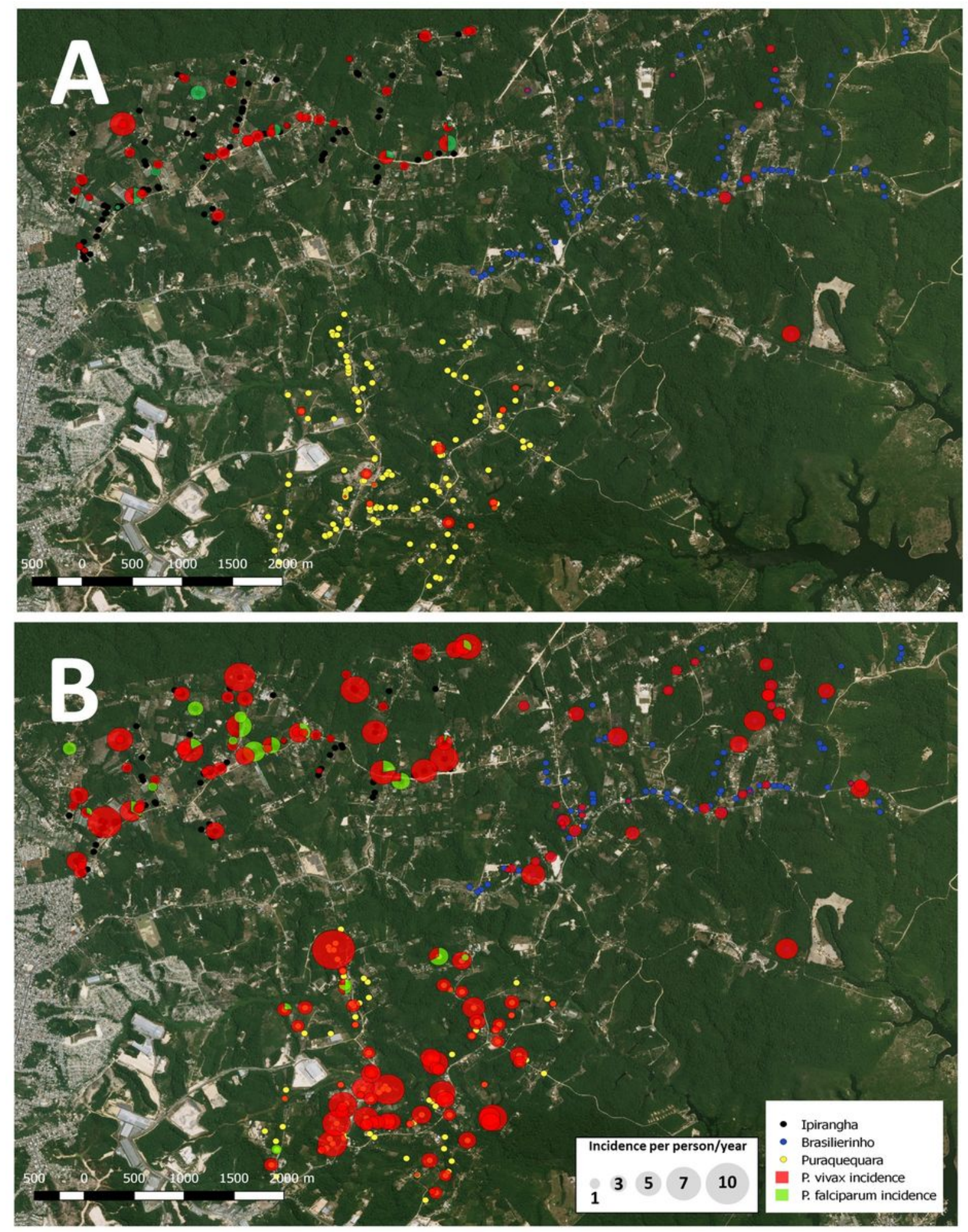

\section{Figure 1}

Spatial representation of clinical P. vivax and P. falciparum cases (Panel A) and qPCR detected P. vivax and P. falciparum infections (Panel B). Data are shown as incidence (cases/detections per person per year, aggregated to the household level). Increased diameter of the circles represents increased incidence. Maps were created using QGIS 2.18, with geodata collected for this study. 

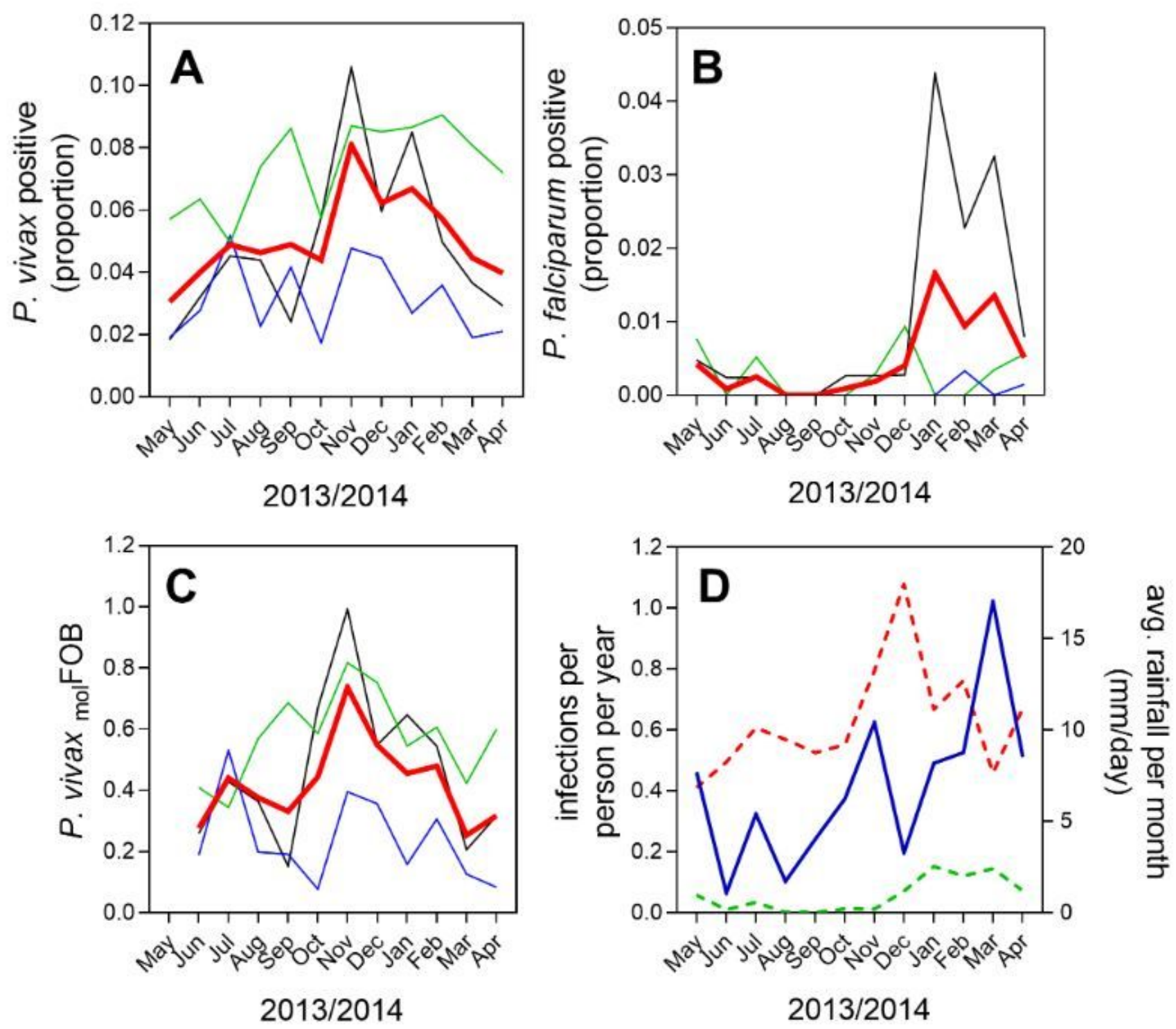
A, B, C: - Ipirangha - Brasilierinho
- Puraquequara
overall
D: - - P. vivax
P. falciparum - Rainfall

\section{Figure 2}

Infection prevalence, molecular force of P. vivax infection and rainfall within the three communities. (A) P. vivax infection prevalence in the three communities, and in in the entire study population. (B) P. falciparum infection prevalence in the three communities, and in in the entire study population. (C) P. vivax molecular force of blood stage infection (molFOB) in the three communities and in the entire population. (D) Rainfall and incidence of P. vivax and P. falciparum infections detected by PCR in the entire study area. 

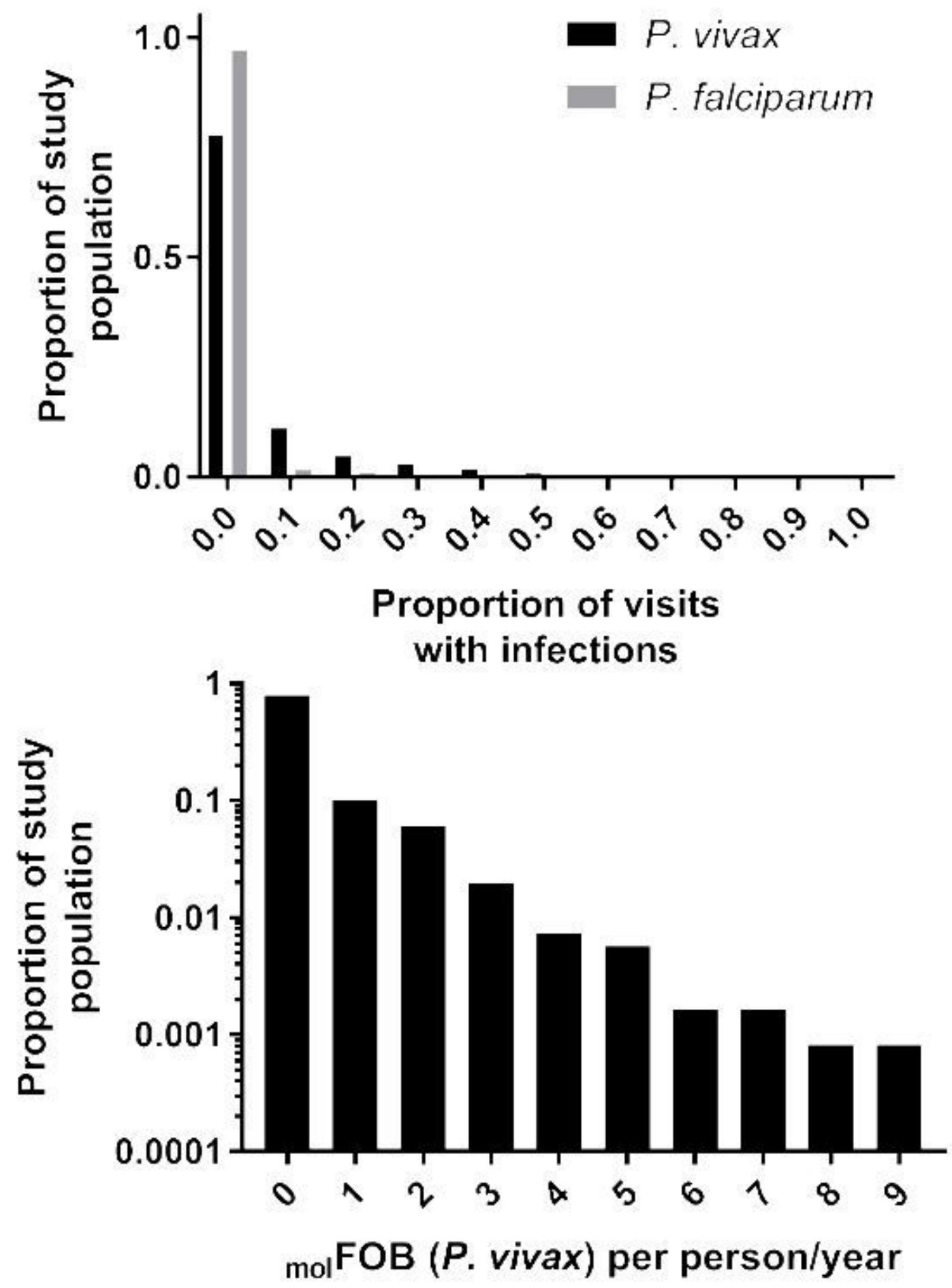

Figure 3

Distribution of Plasmodium infections in the study population. (A) heterogeneity in the incidence of malaria infections. (B) P. vivax molFOB over the entire year of follow-up.

\section{Supplementary Files}


This is a list of supplementary files associated with this preprint. Click to download.

- SupplementaryTable2.docx

- SupplementaryTable5.docx

- SupplementaryTable1.Studydatabase.xlsx

- SupplementaryTable3.docx 